\title{
Alteridad en los roles de género: mujeres pensantes y actuantes en La gran comedia de La Segunda Celestina
}

Por Jorge Trujillo

Universidad de Guadalajara, México 


\section{Dr. Guillermo}

\section{Schmidhuber}

de la Mora

Descubridor de La

gran comedia de la

Segunda Celestina

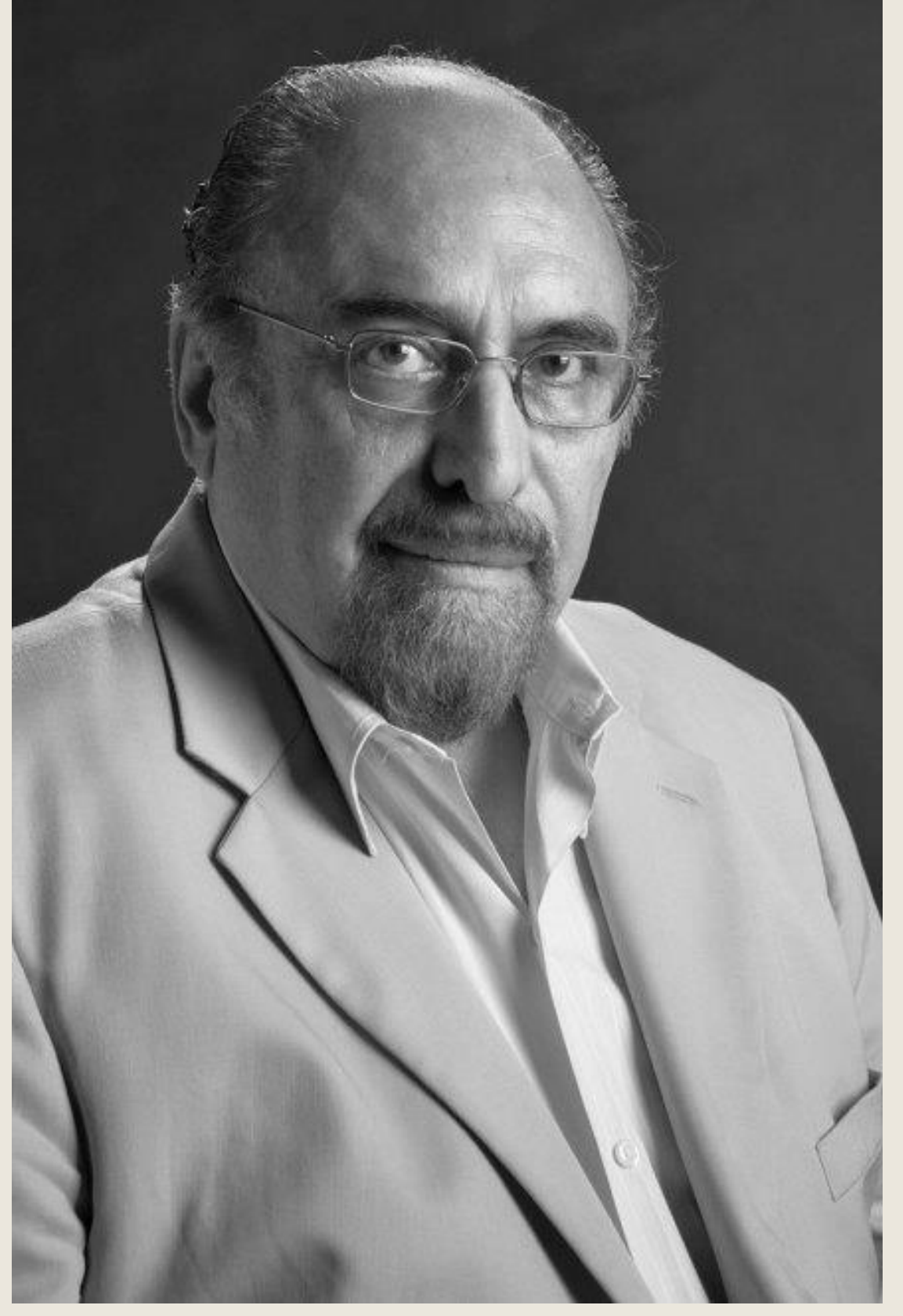




\section{Hallazgo de una}

obra perdida de

Sor Juana: La gran comedia de La

Segunda Celestina

(2007)

GULLLERMO SCHMIDHUBER DE LA MORA 
Suelta de La gran comedia de La

segunda Celestina (British Library

de Londres)

DE LA SEGVNDA

C E L E S T I N A.

FIESTA PARA LOS AÑOS DE LA Reynanueltraleñurazino de 16-6.

DE DON AGVSTIN DE SALAZAR. Pestonasque hablan en ella.

Dotis Ana.
Dothis B Batrite.
Ansons s.

sle Dous Beatrix en reage de cast. -

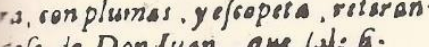

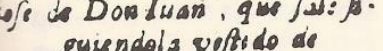

guisndola voffrido ramino.

2o. Canallera, fiadelance allas, hare is yue mi ir fponda a vuefira ofiadia. Iu. B:lla de.dad de eftos borkyeer

mula herinola de Cintis, ie para fier as, y hombres

plomo,y da luz fullninara

equico elBesiode deve

uneaseltaripas corida.

snegros ojos caciender

blanco.pie roluciea;

xemirsile a va alvedrio,
Don Ruan.

Don Dergo

Don Lus. Tacon Mutroe

cue el scred do impuls, fige

de adoraciun veluresria

lin de rarde fer precifa

en que re ulenul quicorolos

a) gुuir tuluz alpirat

Bes.Nomat

Bes. No mas

$\mathrm{C}^{\mathrm{u}}$ aurque diful

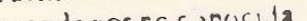

pés de rosrcc r.ucisa

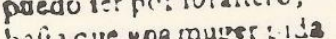

cratra que via ingerp

que no da tigs s, ure

derion

decra cectedecida

quc el fer amainet, y a acafo

quo ceriasí inporáz 


\section{Índice general de}

piezas dramáticas del

teatro antiguo español

desde sus orígenes

hasta mediados del

siglo XVII de Agustín

Cayetano Alberto de la Barrera y Leirado

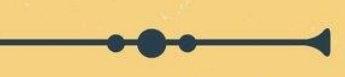

Catálogo Bibliográfico y Biográfico del Teatro Antiguo EsPañol

Desde Sus Orígenes Hasta Mediados del Siglo XVIII

Durán 
"Con el [título] de La segunda Celestina corre en ediciones sueltas, en que la segunda mitad del tercer acto difiere por completo. Creemos que ni una ni otra conclusión pertenece a Salazar, que dejó incompleta su comedia, escrita para festejar los días de doña Mariana de Austria, terminándola cada cual por su parte. D. Juan de Vera y un poeta anónimo" (pp. 457-458).

Marcelino Manéndez y Pelayo

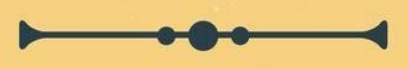

ORÍGENES DE LA Novela

Novelas, Dialogadas, Con un Estudio Preliminar

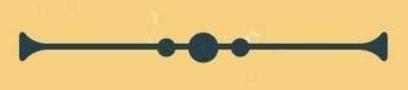

Vol. 3

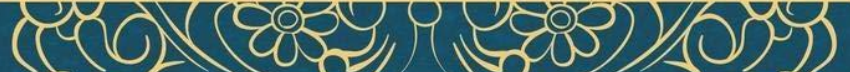

tcol 10202

(2) 


\section{LOS EMPEÑOS DE UNA CASA}

"Pero la Celestina que esta risa os causó, era mestiza

y acabada a retazos,

y si le faltó traza, tuvo trazos,

y con diverso genio

se formó de un trapiche y de un ingenio" (p. 676).

SORJUANA INÉS DE LA GRUZ

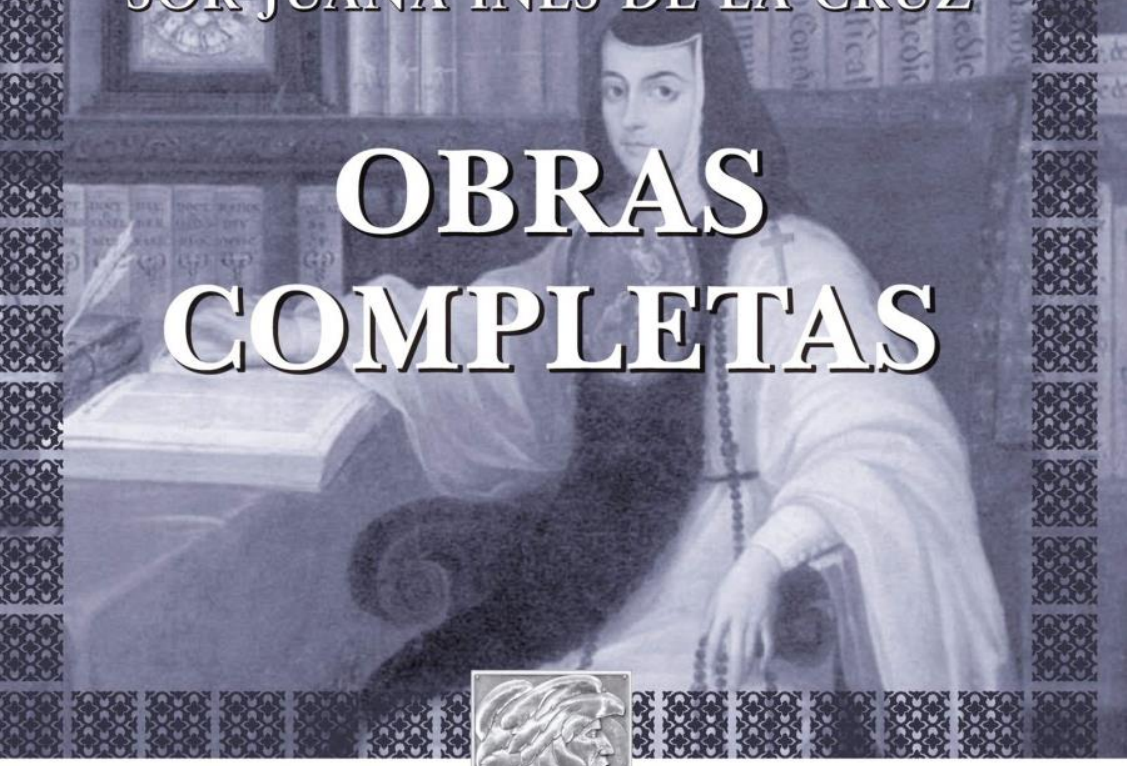
and

PRÓLOGO

FRANCISCO MONTERDE

EX DIRECTOR DE LA ACADEMIA MEXICAN

\section{EDITORIAL PORRÚA}

AV. REPÚBLICA ARGENTINA 15. MÉXICO

"SEPAN CUANTOS..."

Núм. 100 


\section{Guillermo Schmidhuber de la Mora}

Premio Jalisco de Literatura 2017

Guillermo Schmidhuber

Teatro

Narrativa

Ensayos de imaginación

Escritos criticos
Escritos crifticos

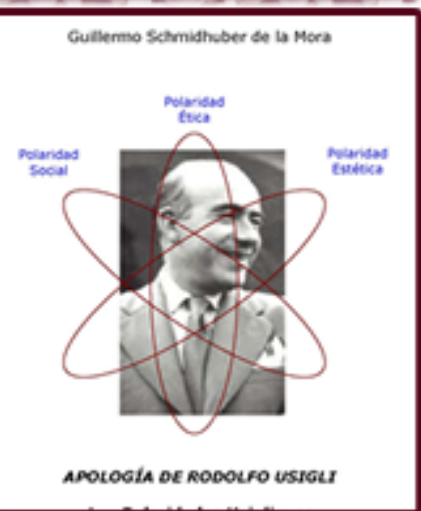

\section{Escritos Críticos}

La gran comedia de La segunda Celestina: indagación autoral

Dorothy Schons, la primera sorjuanista

- Apología a Rodofo Usigli

- El Teatro de Ahora de Juan Bustillo Oro y Mauricio Magdaleno

- La dramaturgia de José Gorostiza

- Francisco Navarro Carranza, dramaturgo jalisciense

- Gonzalo Valdés Medellín, dramaturgo

- Octavio Paz y las trampas de la teología

- Jalisco del origen a la globalización

- El México alucinante de Reinaldo Arenas

- San Luis Leal

- Elvira de la mora, guionista pionera

- Des-Armonía como provocación creadora, LATR

- La historiografía en el teatro español y mexicano

Sobre dramaturgia 
Indagaciones sobre la comedia perdida de Sor Juana Inés de la Cruz

Palabras de Octavio Paz: "Como si la suerte quisiera corresponder al amor y a la dedicación de los estudiosos de sor Juana Inés de la Cruz, en los últimos años han aparecido obras suyas desconocidas o que se creían perdidas. El dramaturgo e investigador Guillermo Schmidhuber da a conocer otro notable hallazgo: el final perdido de La segunda Celestina, la comedia que dejó sin terminar Agustín de Salazar y Torres. Guillermo Schmidhuber demuestra, de manera convincente y detallada, que se trata de una obra juvenil de sor Juana... Algunos de los rasgos de Beatriz y algunas de las expresiones de Celestina son también los de Leonor, retrato de sor Juana y heroína de Los empeños de una casa. Sor Juana ansió siempre retratarse: ¿cómo iba a perder la oportunidad de hacerlo, veladamente, en una comedia que no era suya sino en parte y que no llevaba su nombre? . ¿Azar o justicia poética? Destino Nada más justo también que el joven escritor Guillermo Schmidhuber descubra la comedia perdida de sor Juana. De esta manera el destino ha querido señalarlo doblemente: como lector inteligente de la poetisa y como dramaturgo".

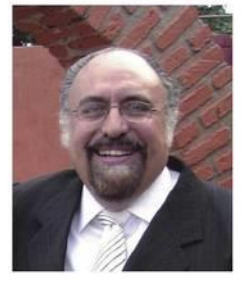

Guillermo Schmidhuber de la Mora

(México, 1943) Es autor y crítico. Su bibliografía abarca más de cien títulos. Doctorado en

Humanidades por la Universidad de Cincinnati. Es uno de los críticos de la obra de sor Juana Inés de la Cruz más destacados, con la especialidad en su dramaturgia y en la localización de sus textos perdidos.

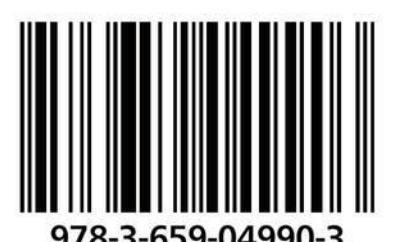

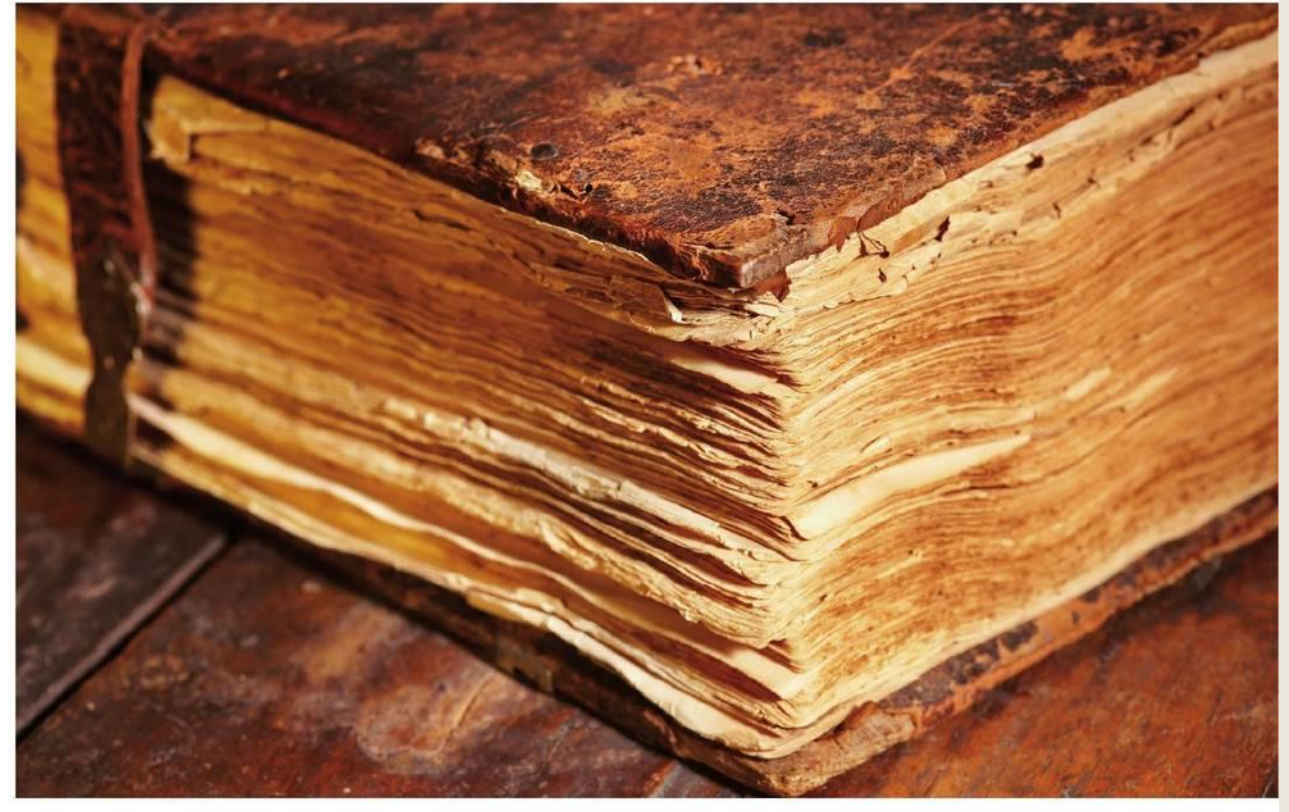

Guillermo Schmidhuber de la Mora

Indagaciones sobre la comedia perdida de Sor Juana Inés de la Cruz

\section{La Segunda Celestina}


Guillermo Schmidhuber en su estudio sobre las comedias de la monja afirma: "El género de 'capa y espada' define a las comedias sorjuanianas no porque las damas sean las protagonistas sino porque son ellas las que determinan la acción dramática, mientras los galanes son receptores de las acciones femeninas" (2007; p. 115). 
LA GRAN

COMEDIA DE

\section{LA SEGUNDA CELESTINA}

FIESTA PARA LOS AÑOS DE LA Reyna nuestra señora, año de 1676.

DE DON AGUSTÍN DE SALAZAR. [coautoría de SOR JUANA INÉS DE LA CRUZ]
SEGUNDO TOMO

DE LAS OBRAS DE

\section{SOR JUANA INÉS DE} LA CRUZ

Y

\section{LA SEGUNDA CBLESTINA \\ (Edicion facsimilar)}




\section{Personas que hablan en ella}

Doña Ana

Doña Beatriz

Antonia

Muñoz
Don Juan

Don Diego

Don Luis

Uno y Dos
Inés

Celestina

Tacón

Alguacil 1 y 2 


\section{TACÓN \\ (2007; pp. 133-134)}

"Celestina, entre las raras

mañas conque se introduce,

es la que en ella más luce

ser remendona de caras".
"Es del amor mandadera,

más su mayor interés

sólo se funda en que es

tan grandísima hechicera". 


\section{CELESTINA (2007; pp. 137-138)}

"Las doncellas más sesudas me creen cualquier disparate como en casamiento trate, y no lo escupen las viudas".
"Mas yo inventé una quimera que es la que más me ha valido; y es que yo mesma he fingido que soy tan grande hechicera". 


\section{CELESTINA}

Bendiga Dios tanto bueno;

puede ese par de bellezas

poner cátedra de damas.

DOÑA ANA

Pues cel ser damas es ciencia?

\section{CELESTINA}

Y tan grande que sí, como

aprendieron en Atenas

el saber filosofía,

el ser damas aprendieran, no habían de conseguido los siete sabios de Grecia. 


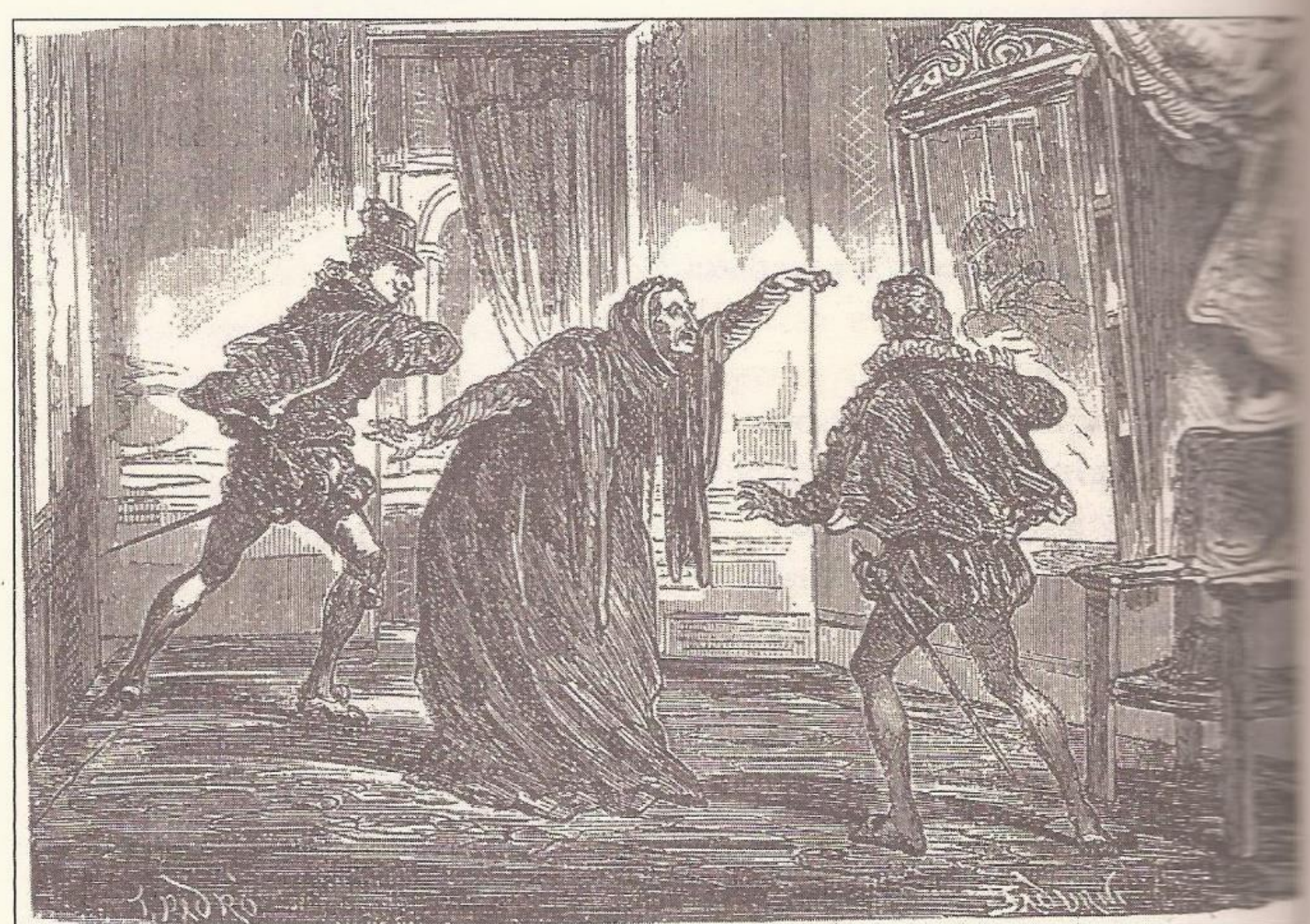

Jornada segunda, escena final. Grabado del catalán Tomás Padró 
ANTONIA (p. 290)

Norabuena, aunque has callado

y nunca lugar ha habido

de agenciar el ser marido

y haberme galanteado, toma esta mano divina, que es envidia del hollín,

y aquí, señores, da fin

La segunda Celestina. 


\section{¡Gracias por su atención!}

